\title{
CASA ABRIGO MÃE DA MATA EM RIO BRANCO - ACRE: EXPERIÊNCIA DE POLÍTICA PARA AS MULHERES
}

\author{
Madge Porto ${ }^{1}$
}

\section{RESUMO}

A partir da perspectiva dos estudos de gênero, este artigo tem como objetivo dialogar com a experiência desenvolvida na Casa Abrigo Mãe da Mata (CAMM), em Rio Branco, capital do Acre. A CAMM atende mulheres em situação de violência tendo como referência o protocolo de orientações e estratégias para a implementação de casasabrigo da Secretaria Especial de Políticas para as Mulheres. A partir do estudo, destacase como resultado principal a proposta de incorporação da figura da monitora no item que descreve a sugestão de quadro mínimo para os recursos humanos das casas-abrigo. A monitora tem a função de acolher as mulheres que recorrem ao abrigo nos momentos de ausências das equipes interdisciplinar e operacional.

\section{PALAVRAS CHAVE}

Gênero. Violência contra as mulheres. Abrigo temporário. Política pública.

\section{SHELTER HOME MÃE DA MATA IN RIO BRANCO, ACRE: AN EXPERIENCE OF POLICIES FOR WOMEN}

\begin{abstract}
Drawing upon gender studies, this article seeks to dialogue with the experience of the Shelter Home Mãe da Mata (CAMM), in Rio Branco, capital of the state of Acre. CAMM provides support and protection to women in situation of domestic violence, following the guidelines and strategies for the implementation of shelter homes supplied by the Special Bureau for Women's Policies. In terms of the conducted research, the main finding is the proposal of incorporating the figure of the mentor in the paragraph that establishes the minimum requirements concerning the human resources employed in the shelter house. The mentor has the function of welcoming the women who resort to the shelter when the interdisciplinary and operational teams are not available.
\end{abstract}

\section{PALAVRAS CHAVE}

Gender. Violence against women. Temporary shelter. Public policy.

\footnotetext{
1 Doutora em Psicologia Clínica e Cultura pela UnB (2013), Mestra em Saúde Coletiva pela UFPE (2002), Professora efetiva da Universidade Federal do Acre, com atuação no Curso de Psicologia. Agradecimentos a Alcinélia Moreira, Filomena Emília Ramos, Joelda da Silva Pais, Joelma Ferreira Franzini, Lenira Pontes e todas que fazem e fizeram parte da Casa Abrigo Mãe da Mata. Agradecimentos também à Maria Liliane Gomes dos Santos e Elainy da Silva Camilo Loiola pela ajuda na formatação do texto.
} 


\section{Introdução}

Este artigo tem por objetivo apresentar a experiência da Casa Abrigo Mãe da Mata $\mathrm{CAMM}^{2}$ tendo como referência as propostas contidas no Programa de Prevenção, Assistência e Combate à Violência Contra a Mulher. (Brasil, 2003), marco das políticas públicas para mulheres em situação de violência. A CAMM foi criada em 2000 pelo Governo do Estado do Acre com apoio do Ministério da Justiça e da Fundação Banco do Brasil para o abrigamento temporário de mulheres e seus filhos e filhas menores de 12 anos em situação de violência.

A escolha desse nome baseouse na lenda da Mãe da Mata, uma sábia senhora, que para os povos da Amazônia cumpre o papel de ser uma grande protetora e defensora da Floresta. Esta entidade mitológica disciplina com rigor aqueles que ousam agredir a floresta e seus habitantes, e assim preserva o seu equilíbrio.

A CAMM é vinculada à Gerência de Equidade de Gênero da Secretaria de Estado de Cidadania e Assistência Social do Acre SECIAS. Esta gerência tem como objetivo a implementação de políticas de enfrentamento e assistência a mulheres em situação de violência de gênero.
Dessa forma, influenciados pela lenda, foram definidos os seguintes objetivos: 1) Abrigar as mulheres e seus filhos e filhas em situação de violência intrafamiliar, garantindo-lhes proteção à vida; 2) Oferecer atendimento social, psicológico, jurídico, oportunidade de profissionalização, visando fortalecer as mulheres para que saiam do ciclo de violência e reconstituamsuasvidas;3) Reduzir os índices de consequências fatais em decorrência da violência intrafamiliar;

4) Evitar a desagregação social e familiar das mulheres e seus filhos/as, ocorrida frequentemente nas situações de violência.

Esses objetivos respondem algumas das importantes demandas do Movimento Feminista, que, ao longo de sua trajetória, influenciou as políticas públicas dirigidas às mulheres. No lastro dessas conquistas, o Movimento Feminista e de mulheres defendeu e conquistou uma instância do poder dentro do Governo Federal: a Secretaria Especial de Políticas para as Mulheres - SPM, com status de ministério e tendo como missão discutir, articular e executar 
políticas para a promoção da igualdade entre mulheres e homens.

Nesse contexto uma política que se destaca é a de enfrentamento à violência contra a mulher. Questão prioritária da pauta Feminista a partir da década de 1960 (Pinto, 2003), e que ainda se apresenta como urgente por influenciar vários aspectos da vida das mulheres e seus filhos e filhas e por demandar diferentes ações do poder público (CAMARGO, 2000; D'OLIVEIRA \& SCHRAIBER, 2000; FRANCO, 2000; HEISE [etal], 1994; SCHRAIBER; D'OLIVEIRA, 1999; SCHRAIBER [et al], s/d; PORTO, 2002; PORTO [et al], 2003).

Dentro das ações de enfrentamento, a SPM apresentou, em 2003, um protocolo de orientações e estratégias para a implementação das Casas-abrigo, que faz parte do Programa de Prevenção, Assistência e Combate à Violência Contra a Mulher. Esse tem o objetivo de atualizar os gestores e profissionais nos aspectos conceituais e metodológicos. (Brasil, 2003)

0 protocolo descreve que:

As Casas-abrigo constituemse em uma das ações de um programa de políticas públicas de prevenção, assistência e combate à violência doméstica e de gênero. (...) são locais seguros que oferecem moradia protegida e atendimento integral a mulheres em situação de risco de vida iminente, em razão de violência doméstica. É um serviço de caráter sigiloso e temporário, onde as usuárias poderão permanecer por um período determinado, durante o qual deverão reunir condições necessárias para retomar o curso de suas vidas (BRASIL, 2003, p. 55).

A partir desse documento houve uma avaliação das ações desenvolvidas na CAMM de forma a avaliar como o trabalho até então desenvolvido estava ou não convergente com a proposta apresentada pelo protocolo da SPM.

\section{Casa Abrigo Mãe da Mata - CAMM: uma política pública para as mulheres do Acre}

OAcreestásituadonachamada Amazônia Sul Ocidental, extremo oeste do Brasil, e faz fronteira com a Bolívia e o Peru. Rio Branco, a capital, tem uma área de 9.877 $\mathrm{km}^{2}$ e sua população é de 335.796 habitantes, segundo o IBGE censo de 2010. Desses, 172.400 são mulheres, o que equivale a $51,34 \%$ da população. Esse estado de federação brasileira conta 
com uma história significativa de luta do movimento de mulheres, datando da segunda metade do século XX os primeiros registros de organização como o movimento das concreteiras (mulheres que quebravam concreto). Contudo, é na década de 1980 que toma maior dimensão. Surgem as primeiras associações, como a Associação das Lavadeiras, a Associação das Quebradeiras de Castanha, o Movimento de Mulheres do Acre - MMA e é implantada a Delegacia de Mulheres do Acre, a terceira implementada no Brasil. Ainda nessa época, surge a Rede Acreana de Mulheres e Homens, Organização não governamentalONG feminista com importante papel na organização das mulheres urbanas e rurais.

Nos anos 1990, o Centro de Direitos Humanos e Educação Popular do Acre - CDHEP realiza a primeira pesquisa sobre a violência física e sexual contra a mulher, contribuindo para dar visibilidade ao fenômeno da violência na capital e para a necessidade de implantação de políticas públicas para o enfrentamento à violência de gênero.

Nesse contexto, em 1994, é inaugurada pela Prefeitura Municipal de Rio Branco, a Casa Rosa Mulher, um espaço de atendimento às mulheres em situação de violência e risco social. Em 1999, o Governo do Acre criou, no âmbito da Secretaria de Cidadania e Assistência Social ${ }^{3}$, o Departamento de Relações Sociais de Gênero, nomeada posteriormente de Gerência de Equidade de Gênero, com o objetivo de promover e garantir a equidade de gênero nas áreas de cidadania e assistência social, além da criação da Secretaria Extraordinária da Mulher do Governo do Estado do Acre. Na Gerência de Equidade de Gênero priorizou-se três áreas de atuação: saúde da mulher, geração de emprego e renda e combate à violência contra a mulher, e nesta área, implementou o projeto de criação da Casa Abrigo Mãe da Mata, representando a incorporação, pelo Estado, de importante bandeira do Movimento Feminista. Com a estruturação da Secretaria Extraordinária da Mulher também pelo executivo estadual, no ano de 2003, a Gerência redefiniu seu papel, ficando com a responsabilidade

\footnotetext{
3 A partir de 2007, Secretaria de Estado de
} Desenvolvimento Social - SEDS. 
da implementação das políticas de enfrentamento à violência.

Segundo Nascimento (2013): em 2007 extingue-se a Secretaria Extraordinária da Mulher e cria-se a Assessoria Especial da Mulher, que na avaliação do movimento de mulheres foi um recuo imenso e um equívoco de gestão no que se refere a políticas para mulheres. Não basta ter um "olhar" feminista para uma intervenção qualificada, é necessário recursos humanos e financeiros. No ano de 2005, a prefeitura de Rio Branco cria a Coordenadoria Municipal da Mulher, e em 2010, o governo do Estado cria novamente a Secretaria de Políticas para as Mulheres. Isto seguramente embala na correlação de forças para firmar a ideologia feminista como um aporte necessário no que diz respeito a políticas para mulheres (p. 81).

\section{Relato de uma experiência: as mulheres e o abrigo - a CAMM e o protocolo da SPM}

Para a implementação do projeto da CAMM foi construído um imóvel projetado com dimensões adequadas para servir de abrigo e acolher trinta pessoas entre mulheres e crianças e/ou adolescentes, localizado em um bairro residencial de Rio Branco e tendo seu endereço mantido sob sigilo. A CAMM começou a receber as primeiras abrigadas em janeiro de 2001, após uma capacitação inicial com a equipe sobre a temática da violência e sobre os atendimentos que deveriam ser realizados, a partir de então. Quanto ao objetivo geral de "garantir a integridade física e/ou psicológica de mulheres em risco de vida e de seus filhos de menor idade - crianças e/ou adolescentes, favorecendo o exercício de sua condição cidadã e de seu valor de pessoa sabedora de que nenhuma vida humana pode ser violentada" (Brasil, 2003, p. 55), há uma convergência entre a proposta da CAMM e do protocolo da SPM. Já com relação aos objetivos específicos propostos pela SPM existem algumas diferenças, pois o protocolo orienta como objetivos específicos:

Promover atendimento integral e interdisciplinar às mulheres e seus filhos de menor idade, em especial nas áreas psicológica, social e jurídica; Promover condições objetivas de inserção social da mulher, conjugando as ações da casa-abrigo a programas de saúde, emprego e renda, moradia, creches, profissionalização entre outros; Prover suporte informativo e acesso a serviços, instruindo as mulheres para reconhecerem seus direitos como cidadãs e os meios para efetivá-los; Proporcionar ambiente e 
atividades propícios para que as mulheres possam exercitar sua autonomia; Proporcionar ambiente e atividades propícios para recuperar sua autoestima; Prover meios para o fortalecimento do vínculo mãe/ filhos, favorecendo modos de convivência não-violentos; Promover o resgate dos vínculos entre pai e filhos, fortalecendo os aspectos saudáveis da relação (BRASIL, 2003, pp. 55-56).

Com relação ao resgate da relação entre pais e filhos/as, não há nenhuma ação e nem mesmo previsão para essa ação no projeto da CAMM. Todavia, apesar desse aspecto ser avaliado por todas as instâncias da Secretaria de Estado de Cidadania e Assistência Social - SECIAS como importante, esse objetivo não foi acrescido aos objetivos do abrigo, por uma decisão política - de realizar um atendimento para as mulheres - e administrativa, por falta de estrutura para tal ação.

A metodologia proposta pelo protocolo está fundada nos seguintes pressupostos:

1. A violência doméstica e de gênero não respeita fronteiras de classe, raça/etnia ou geração; 2. Não basta proporcionar meios de sobrevivência para que ocorra o rompimento da relação violenta; 3. A autogestão do espaço de moradia é importante para promover a construção da autonomia; 4. Resgatar um espaço próprio para as crianças; 5. Promover a escuta não julgadora; 6. A violência deve ser compreendida como relacional (BRASIL, 2003, p. 59).

Esses pressupostos tornaramse uma base importante para a realização das capacitações que a equipe identificava como fundamentais para a efetivação das ações. A atuação em rede, ou seja, articulada com outras instituições para responder as necessidades das mulheres, foi se fortalecendo tendo como referência as orientações sobre:

Educação e promoção à saúde física e mental; promoção e inserção profissional; acesso à justiça e à promoção da cidadania; promoção de estratégias de acesso à moradia; promoção da inserção escolar e ações pedagógicas recreativas e reflexivas aos seus filhos menores sobre sua vivência em uma família em situação de violência (BRASIL, 2003, p. 59).

É importante destacar que esse tipo de atuação foi percebida como fundamental e, dessa forma, pôde ser construída a partir da necessidade de cada caso. Aos poucos a rede articulada pela CAMM foi se formando e se apresentando como fundamental, assim como estava apresentada 
no protocolo da SPM. Quanto às estratégias de ação para promover a concretização dos objetivos geral e específico assumidos por uma casa-abrigo, a SPM propõe em seu protocolo: interdisciplinaridade; autogestão; capacitação da equipe; abordagem de grupo; abordagem critica em questões de gênero.

Todas estas estratégias passaram a ser utilizadas de forma planejada e sistemática com resultados muito positivos como o estabelecimento de um cronograma de capacitação e supervisão, e a discussão do regimento interno. Em relação ao espaço físicodaCAMMestádividido nas seguintes dependências: guarita para vigilantes, garagem para o veículo (tipo kombi), sala de estar, sala da gerência, sala de Serviço Social, jardim interno, sala de atendimento psicológico, sala de recreação, pátio externo, sala do espaço educativo, refeitório coletivo, cozinha, lavanderia coletiva, dez suítes, sendo uma utilizada para o alojamento das monitoras e outra para depósito, horta e quintal arborizado. Provisoriamente os medicamentos e primeiros socorros permanecem no quarto destinado ao alojamento das monitoras.
0 protocolo da SPM descreve um padrão mínimo para a implementação de uma moradia protegida com o intuito de preservar a qualidade do atendimento nos serviços prestados. Este padrão mínimo é apresentado sob dois aspectos: recursos humanos e materiais. No que se relaciona aos recursos materiais, oferece como referência:

a) Imóvel de dimensões adequadas para abrigar $o$ número estabelecido de mulheres e seus filhos de menor idade, em local que favoreça a segurança e o sigilo e considerando-se a necessidade de: localização do abrigo, de preferência em área residencial, não contando com presença aparente de guaritas, placas de identificação, podendo oferecer um ambiente discreto e propício; Espaço para dormitórios, onde a mulher possa acomodar seus pertences pessoais, mantendo o vínculo familiar e garantindo sua privacidade; Espaços de convivência coletiva (salas de reuniões, grupos e oficinas); Espaços para o refeitório e cozinha coletivos; Espaço para recreação das crianças, preferencialmente contando com áreas externas; Local adequado ao atendimento de primeiros socorros, guarda de medicamentos e outras ações de profilaxia em saúde; Espaço para lavanderia coletiva; Dependências sanitárias 
compatíveis com o número de pessoas abrigadas; Adequação da estrutura do imóvel aos portadores de necessidades especiais; e b) Infra-estrutura administrativa de comunicação e de transporte (BRASIL, 2003, p. 62).

Fazendo uma análise comparativa pode-se afirmar que a estrutura da CAMM se adequa às orientações do protocolo, principalmente, no que se refere ao espaço físico. Contudo, há alguns pontos que merecem uma discussão. Quanto à garantia da segurança e do sigilo faz-se necessário algumas considerações. Em uma cidade pequena como Rio Branco garantir o sigilo da localização da casa-abrigo é algo muito difícil. Mesmo cumprindo algumas das orientações do protocolo como está localizada em um bairro residencial e não ter placa de identificação, a CAMM é um espaço facilmente localizável. 0 principal elemento que contribui para isso é o conhecimento do endereço pela polícia civil. As mulheres são levadas da Delegacia Especializada de Atendimento à Mulher - DEAM até a CAMM em um carro da delegacia, o que faz com que os policiais conheçam seu endereço, assim como outras instituições que compõem a rede de enfrentamento à violência, sem contar com o fluxo de mulheres e de carros oficiais que despertam curiosidade na vizinhança.

Essa situação já provocou episódios como, por exemplo, os maridos agressores chegarem até a porta da CAMM portando um crachá de uma instituição pública que faz parte da rede de enfrentamento à violência conta a mulher ou fardados para adentrarem no abrigo no momento em que suas esposas estavam abrigadas. Dessa forma, a segurança no abrigo apresenta-se frágil, apesar da guarita, do muro alto e da cerca elétrica.

No bordão popular, Rio Branco é conhecida como uma cidade de "muros baixos", ou seja, uma cidade onde tudo que acontece é comentado e se sabe o que acontece na casa ao lado. Esse é outro aspecto que corrobora para que o endereço da CAMM seja de conhecimento de muitas pessoas na cidade e que tenha passado por alguns momentos de ameaça à segurança das servidoras e das mulheres abrigadas. Outra questão que deixa tanto as mulheres abrigadas 
quanto à equipe em situação de vulnerabilidade é a necessidade de elas saírem do abrigo para acessar os serviços de saúde. Essa saída é feita no carro da CAMM e as mulheres são acompanhadas pelas monitoras e pelo motorista. É um momento de muito perigo, pois numa cidade pequena, a probabilidade das pessoas se encontrarem é muito grande fazendo com que as mulheres corram o risco de encontrarem o próprio agressor ou alguém que o conheça e informe alguma pista do seu paradeiro.

Uma sugestão para diminuir esses riscos seria evitar o encaminhamento das mulheres diretamente pela DEAM, de forma que a delegacia levasse as mulheres a um lugar estratégico da SECIAS e esta fizesse imediatamente, em um carro não identificado, o transporte das mulheres até a CAMM. Com relação às saídas para o atendimento médico e jurídico seria importante formar a equipe de apoio técnico, sugerida pelo protocolo da SPM (Brasil, 2003, p. 61), além de pensar uma estratégia de segurança para as saídas que não podem ser evitadas, considerando os riscos e dificuldades de cada caso.

\section{A capacitação continuada da equipe}

O protocolo da SPM apresenta entre as estratégias de ação a capacitação da equipe em que a sugestão é a "promoção da capacitação, educação continuada e supervisão da equipe interdisciplinar dentro da ótica da violência de gênero" (Brasil, 2003, p. 60). Na CAMM a capacitação realizada foi chamada de Capacitação Continuada - CC e tinha como foco de intervenção a equipe técnica/interdisciplinar. Foi uma iniciativa da Gerência de Equidade de Gênero - GEG e teve como objetivo principal dar um suporte emocional ao grupo, pois se compreendia que o trabalho ali realizado tinha uma natureza provocadora de tensão.

É importante destacar que um trabalho como esse só é possível quando existe uma equipe estruturada com uma assessoria técnica, uma gerência administrativa e pessoal de apoio comprometido com o trabalho. Só assim foi possível possibilitar o desenvolvimento das atividades como as que estão sendo apresentadas nesse artigo. 
Outro ponto relevante se refere à compreensão da importância da proposta pela gestora da GEG. Esta percebeu que o suporte sistemático e emocional dado à equipe da CAMM seria de fundamental importância para o desenvolvimento das ações de enfrentamento à violência contra $\mathrm{a}$ mulher. Dessa forma, esse suporte "de retaguarda", que foi também chamado de apoio às cuidadoras, passou a ser entendido e realizado como uma política de intervenção da Gerência de Equidade de Gênero, a partir de então.

0 suporte oferecido à equipe técnica/interdisciplinar pela CC visibilizava a vivência de conteúdos tristes, que causavam dor, revolta e sentimentos de frustração e/ou impotência diante das situações vividas pelas mulheres por parte dessa equipe. Assim, apoiadas nos pressupostos da SPM, a abordagem realizada com a equipe foi de iniciar um trabalho de apoio teórico e técnico às atividades desenvolvidas com as abrigadas e seus filhos e filhas.

Assim como Alves e CouraFilho (2001), que referem à necessidade de CC dos recursos humanos, de programar o atendimento psicológico para equipe técnica e o aprofundamento sobre o complexo objetivo do trabalho, bem como as implicações desse tipo de trabalho no cotidiano das mulheres, a equipe da GEG entende a importância e a necessidade de sistematizar uma capacitação continuada na CAMM como uma ação prioritária.

Nesse processo houve a realização de encontros para identificar as necessidades de formação e capacitação da equipe e, também, a proposta de encontros chamados de "Intercontrole" supervisão clínica realizada na instituição, com a psicóloga lotada na CAMM, numa forma de criar um espaço de apoio, discussão técnica e teórica dos casos e da intervenção psicológica que estava sendo desenvolvida.

No período de abril a dezembro do ano de 2003, foram realizados dezesseis encontros de capacitação com a equipe técnica. Estes eram apresentados com momentos de formação e informação, no entanto os temas e a forma de desenvolvê-los tinham o objetivo de possibilitar um espaço para a fala e para a abordagem de sentimentos suscitados no 
decorrer do trabalho desenvolvido na CAMM, como: raiva ou frustração porque a mulher voltou a morar com o autor da violência; medo e dor diante de um caso que pouco se podia fazer, revolta pela falta de resposta de alguma instituição que compõe a rede de enfrentamento à violência contra as mulheres.

A cada encontro o grupo aprofundava seus questionamentos e expressava mais suas dificuldades. No início houve uma resistência, que, posteriormente, foi revelada como fruto dos trabalhos desenvolvidos anteriormente: espaços de capacitação que não consideravam as necessidades e as dificuldades das cuidadoras, o foco era a abrigada ficando a experiência vivida pelas integrantes da equipe sem lugar, ou seja, desconsideradas.

No início do segundo mês de capacitação, houve uma compreensão de que o trabalho proposto era diferente, que mesmo que estivessem "fazendo errado" poderiam ser acolhidas em suas dificuldades e teriam o suporte técnico e teórico necessários. As servidoras começaram, de forma lenta, a perceber o papel da CAMM e cada uma, o seu próprio papel, suas angústias, medos, dúvidas. Agora tinham a quem recorrer.

A partir da compreensão de que toda a equipe de alguma maneira estaria interagindo com as abrigadas e de que a questão da violência mobilizava a todas/os, foi estruturado um momento de capacitação para a equipe de apoio formada por vigias, cozinheiras, auxiliares de cozinha e instrutora. 0 trabalho desenvolvido teve a seguinte forma: encontros quinzenais de aproximadamente três horas. Era apresentado um estímulo - filme, texto, pergunta, dinâmica de grupo - e a partir daí o grupo passava a se posicionar, discutir, fazer comparações com o que viviam, sendo trabalhados principalmente temas como: gênero, violência contra a mulher, intervenções em instituições e o protocolo de orientações e estratégias para a implementação das Casas-abrigo (Brasil, 2003).

Os encontros, à medida que os temas eram discutidos, promoviam uma maior exposição de sentimentos por parte das cuidadoras: raiva dasabrigadas por romper o casamento ou por voltar 
para o autor da violência, por não cuidar de suas crianças ou por não realizar as tarefas que lhe cabiam na CAMM. Era comum a queixa que depois que a abrigada se acalmava e se adaptava àquela situação passava a cobrar da equipe como que esta fosse sua "empregada". $\mathrm{Na}$ realidade, a queixa se refere ao não reconhecimento, por parte da abrigada, do trabalho realizado pela equipe, dentro de um contexto de muitas limitações, que oferece para ela oportunidades que esta não "aproveita".

Outro tema que surgiu foi a experiência pessoal com a violência, situação também observada por Meneghel [et al] (2000). Algumas servidoras começaram a relatar a vivência de violência em suas relações familiares. Ao longo dos encontros existiam depoimentos em que as servidoras relatavam situações de violência vividas por elas, por suas filhas e/ou mães. Havia emoção, silêncio, vergonha e certo espanto. Contudo, apesar de parecer que o grupo sabia da experiência da violência da colega, o relato público chocava, incomodava e constrangia. Ao mesmo tempo, aquelas que viviam em situação de violência, mas não a tornava pública nos encontros, tinham suas histórias comentadas no abrigo pelas colegas que não sabiam "como ajudar". Eram mulheres que apresentavam dificuldades na execução de seu trabalho, que buscavam apoio de forma indireta, - adoecimentos de ordem psicossomática, "problemas com o marido" que não eram explicitados em sua natureza - mas não assumiam sua situação.

\section{Equipe multiprofissional e} interdisciplinar: uma avaliação a partir da experiência

A equipe de profissionais da CAMM passou por mudanças, ao longo de seu funcionamento, novos profissionais foram admitidos e cargos foram criados, ficando com a equipe de servidores composta por: gerente, gerente administrativo, assistente social, servidoras de apoio administrativo ao serviço social, psicóloga, coordenadora pedagógica, recreadora infantil, professora, digitadora, instrutora de bordado e/ou salão de beleza, monitoras, vigias, cozinheiras, auxiliar de cozinha, zeladoras e motorista.

0 protocolo da SPM 
apresenta uma proposta para os recursos humanos - equipes interdisciplinar, de apoio técnico e operacional, a saber:

a) Equipe Interdisciplinar permanente que contaria com profissionais de nível superior para atender às áreas de saúde física, mental e promoção de cidadania, além de uma coordenadora para a casaabrigo. Estes profissionais devem estar lotados na Casaabrigo e fazer parte da equipe permanente. Sugestão de quadro mínimo: Psicólogo e Assistente Social (Brasil, 2003, p. 61).

A CAMM consegue manter na maior parte do tempo esse quadro mínimo de profissionais de nível superior. Contudo, as dificuldades com relação ao vínculo transitório dessas profissionais (contratos temporários) geram uma rotatividade que promove uma sensação constante de recomeço.

b) Equipe de Apoio Técnico, composta por profissionais de nível superior, que dêem suporte às áreas de nutrição, pedagógica e educação continuada à equipe, assim como garantam orientação e assistência jurídica às moradoras da Casa-abrigo pela Defensoria Pública do Estado e na falta desta, por Advogados designados pela seção local da Ordem dos Advogados do Brasil (OAB), Universidades e órgãos afins. Nesse caso, os profissionais poderão estar vinculados a outros serviços, atuando em tarefas específicas junto à Casa-abrigo. Sugestão de quadro mínimo: Nutricionista, Pedagogo, Enfermeiro, Advogado (Brasil, 2003, p. 61).

A CAMM sempre teve limites com relação a essa equipe de apoio. Não havia uma preocupação, até então, de formála, pois os problemas de saúde física e mental mais graves ou mais urgentes eram encaminhados ao sistema de saúde. 0 apoio jurídico é realizado, dependendo do caso e das articulações feitas, pela defensoria pública ou pelas assessoras jurídicas da Secretaria Extraordinária da Mulher do Estado.

No que se refere à equipe operacional, há a seguinte descrição: "profissionais de nível médio e/ou básico que atuem no provimento da infra-estrutura. "Sugestão de quadro mínimo": Agente Administrativo, Cozinheiro, Auxiliar de Conservação e Limpeza, Vigilante e Motorista". (Brasil, 2003, p. 61). A partir dessa comparação pode-se dizer que na CAMM há uma estrutura muito próxima da proposta apresentada pela SPM.

Em todo o caso, duas questões 
se destacam: 1) a falta da equipe de apoio técnico na CAMM, que faz com que as mulheres precisem sair para ter o atendimento, que poderia ser dado por essa equipe no abrigo, aumentando assim, a vulnerabilidade já discutida anteriormente e 2) a falta, no protocolo da SPM, de uma profissional que desempenhe a função a qual foi denominada de monitora.

Na CAMM as monitoras têm as seguintes atribuições funcionais: Receber e notificar (ficha de recebimento) as informações sobre as abrigadas que chegam no horário de plantão e final de semana; Observar o estado emocional das abrigadas para informar no relatório de plantão; Registrar os pertences das abrigadas na entrada; Atender as necessidades imediatas: ouvir a queixa, acolher o choro, verificar se a mulher e seus filhos precisam de alimento; Informar sobre o funcionamento e normas da casa e apresentar as pessoas da casa; Zelar pelas instalações físicas da casa, pelos horários das refeições, do descanso e pela segurança das abrigadas, fechando as portas do prédio do dormitório; Zelar pela limpeza da Casa e verificar se as abrigadas estão zelando pela limpeza dos seus apartamentos e cumprindo a escala préestabelecida de limpeza do espaço coletivo (ACRE, 2003).

Nos momentos que a equipe interdisciplinar está ausente cabe às monitoras: intervir em situações de tensão entre as abrigadas e entre seus filhos (gerenciar conflitos); não permitir saída não comunicada pela gerência das crianças e adolescentes; solicitar para as mulheres, no momento de saída, a assinatura do termo de desligamento e a chave do apartamento; devolver os pertences das abrigadas no momento do desligamento; Comunicar à equipe técnica as emergências; Trabalhar em constante informação com os vigilantes; Controlar os medicamentos prescritos para as abrigadas e seus filhos/as (explicando como usá-los ou fazendo a medicação caso a abrigada não tenha condições de fazê-la); Participar da capacitação continuada e das reuniões de estudo de caso (ACRE, 2003).

Diante disso, a equipe questionava como uma casa- 
abrigo poderia funcionar sem essa profissional, pois o papel que as monitoras desempenhavam era considerado por toda a equipe como fundamental, a ponto de se pensar inviável a CAMM sem as monitoras. Isso porque não há referência no protocolo da SPM sobre a necessidade de uma profissional que faça plantões para que, independente da hora que as mulheres cheguem ao abrigo, haja uma acolhida por uma profissional treinada e que esteja lá para recebê-la. Para um abrigo que funciona $24 \mathrm{~h}$ como a CAMM faz-se necessário uma profissional que possa receber e liberar as mulheres nos momentos que a equipe interdisciplinar e/ ou a coordenadora do abrigo não estiverem presentes. A experiência da CAMM mostra que um dos momentos mais difíceis é a entrada no abrigo: as dúvidas, a dor, a vergonha e, esse momento não tem horário. Assim, o papel da monitora tem uma relevância fundamental quando o objetivo do atendimento é a "assistência integral" à mulher (BRASIL, 2003, p. 59). Nascimento (2013) afirma que por plantão ficam escaladas duas monitoras e que a "Cada saída do espaço físico da casa também é computada, pois isso demanda recursos materiais e humanos, como carro com motorista, uma monitora para acompanhar" (p. 96).

Não se pode pensar a assistência integral só quando a equipe interdisciplinar está presente, a não ser que essa equipe funcione em sistema de plantão - que não é o caso da CAMM. Há a necessidade de alguém que acolha a entrada das mulheres no abrigo, pois o momento posterior a decisão de sair de casa, muitas vezes com os filhos/as e a roupa do corpo, é de um desamparo intenso. Chegar a um lugar desconhecido depois de ter abandonado a casa, os pertences, a vida que viveu até então, é difícil. A mulher precisa de apoio, conforto, escuta, mesmo que seja à noite, na madrugada ou no fim de semana. Principalmente quando estudos apontam que as agressões às mulheres têm uma frequência maior à noite (Lopes [et al], 2004).

A monitora propicia, ainda, uma base para que a equipe desenvolva as ações necessárias, pois as mulheres já começaram a ser atendidas, já houve um 
acolhimento que favorece a constata o crescimento dos construção de uma relação de abrigamentosaolongo dosanos de confiança com a equipe.

Perfil das mulheres atendidas pela CAMM

Pensar sobre a importância do trabalho da monitora, em especial na possibilidade de acolhimento que esta pode realizar num abrigo para mulheres em situação de violência, foi uma questão avaliada como fundamental, principalmente quando se funcionamento da CAMM. Todavia, é importante destacar que este crescimento pode ser justificado mais pela divulgação do serviço oferecido pelo abrigo que por um aumento desse tipo de violência. Contudo, o que se observa é que o número de abrigamentos anuais na CAMM aumentou, como pode ser verificado no quadro abaixo.

Quadro 01 - Comparação entre os abrigamentos das mulheres, crianças e adolescentes por ano na CAMM (2001 a 2005)

\begin{tabular}{|c|c|c|c|}
\hline Ano - jan a dez & $\mathrm{N}^{o}$ de Mulheres & $\mathrm{N}^{0}$ de crianças e adolescente ${ }^{4}$ & Total \\
\hline 2001 & $49(39,52 \%)$ & $75(60,48 \%)$ & 124 \\
\hline 2002 & $96(47,76 \%)$ & $105(52,24 \%)$ & 201 \\
\hline 2003 & $149(44,61 \%)$ & $185(55,39 \%)$ & 334 \\
\hline 2004 & $152(44,71 \%)$ & $188(55,29 \%)$ & 340 \\
\hline 2005 até novembro & $182(42,62 \%)$ & $245(57,38 \%)$ & 427 \\
\hline TOTAL & $628(44,04 \%)$ & $798(55,96 \%)$ & 1.426 \\
\hline
\end{tabular}

Fonte: Relatório Perfil do Abrigamento na CAMM, realizado pela Gerência de Equidade de Gênero.

Esses dados revelam destaca "Foram examinados os informações importantes: relatórios dos anos de 2007, 2008, 1. Aumento progressivo dos 2009, 2010 e 2011. Durante esse abrigamentos que corresponde período, passaram pela Casa a 344,35\% quando se compara Abrigo Mãe da Mata cerca de 700 2001 com 2005 e 2. A proporção mulheres e cerca de 1200 crianças de crianças e adolescentes com idade variando entre 0 a 15 abrigadas apresentou-se em anos" (p. 95). Assim, observa-se todos os anos maior que a das que de 2007 a 2011 um total de mulheres. Nascimento (2013) aproximadamente 1900 pessoas

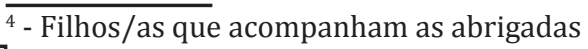


abrigadas (mulheres e crianças) e quando somado ao primeiro período investigado, 2001 a 2005, tem-se um montante de 3.326 abrigamentos e um aumento de 14\% aproximadamente num período de cinco anos da primeira estimativa. É importante destacar que o abrigamento de uma mulher em situação de violência é também uma ação preventiva com relação às crianças e os adolescentes, pois estes também ficam vulneráveis nas situações de violência de gênero. Assim, o rompimento do ciclo da violência intrafamiliar se apresenta como um aspecto fundamental na proteção e apoio a essa faixa etária.

Duhamele e Fortin (2004), estudando a relação entre aumento da violência contra crianças filhas de mulheres que estão em situação de violência doméstica, identificaram que o nível de tolerância em relação à violência contra criança era um bom preditivo do uso desse tipo de violência. Referem que o estudo ratifica um dado há muito tempo observado-associaçãodaviolência contra a mulher e a violência contra as crianças. Entretanto, destacam que, contrariando algumas expectativas, observaram uma relação inversamente proporcional entre a intensidade de violência sofrida pela mulher e a violência com que tratava as crianças. Para esses autores esse dado é interessante, pois aponta que a relação entre violência doméstica e abuso contra crianças é algo complexo e não se estabelece de forma linear.

Todavia, embora se faça necessário mais estudos quanto à relação entre violência contra a mulher e abuso contra as crianças, e que, mesmo com os resultados de Duhamele e Fortin (2004), não podemos entender que a violência contra a mulher seja um fator protetório para as crianças. Viver em situação de violência, mesmo que não se seja alvo direto dela, traz consequências como os próprios autores apresentam - violência contra a mulher fator de risco para violência contra a criança. Todavia, embora a intensidade da violência contra as crianças diminua à medida que a violência contra a mulher aumenta, não determina a ausência de consequências negativas na vida das crianças que vivem em lares mediados pela violência (BRANCALHONE 
[et al], 2004; MENEGHEL [et al], 2000, REICHENHEIM [et al], 1999, MALDONADO \& WILLIAMS, 2005).

Foi a partir de 2003 que algumas informações sobre as mulheres abrigadas começaram a ser tabuladas pela GEG da SECIAS. Dessa forma, passouse a ter uma estimativa sobre algumas características das mulheres, das agressões e dos atendimentos realizados pela CAMM. É importante destacar que os dados ora apresentados estão sujeitos a falhas, pois se trabalhou com as informações que foram registradas. Sabe-se o quanto é difícil trabalhar com informações e registros que são fruto do atendimento, pois não há a preocupação de registrar com o rigor que seria necessário para possibilitar algumas afirmações mais fidedignas (CAMPOS, 2001), mas é uma forma de se ter uma referência mínima sobre o trabalho realizado. Outro ponto importante é que a partir desse material, está existindo uma ação para melhorar a qualidade das informações a serem coletadas, de forma que a cada ano as informações revelemse mais confiáveis.

Outro ponto importante é que a CAMM recebe mulheres em situação de violência de gênero, doméstica e em risco de morte (69,52\%). Seu objetivo principal, contudo, é receber também mulheres que sofrem outros tipos de violência: violência social e/ou institucional, violência cometida por desconhecidos ou violência contra as adolescentes $(34,45 \%)$, que não deixam de ser tipos de violência contidas na definição de violência de gênero (SCHRAIBER [et al], s/d).

Entre janeiro de 2003 e dezembro de 2004 ficaram abrigadas na CAMM 301 mulheres e 373 crianças e adolescentes filhos e filhas destas. São mulheres jovens, de 18 a 34 anos (65,11\%), com uma escolaridade muito baixa - mais de $12 \%$ não são alfabetizadas e 57,81\% têm o Ensino Fundamental incompleto. Apenas 7\% referem casamento formal e 72,76\% são referidas como negras e pardas. Quanto à profissão, $52,16 \%$ se dizem do lar, $11,96 \%$ domésticas e $5,65 \%$ vendedoras. $\quad 58,8 \%$ ficaram abrigadas junto com os filhos e filhas. (Acre, 2005)

Atualizando essas informações a partir do estudo de 
Nascimento (2013), destacamos:

Em sua imensa maioria, são mulheres com ensino fundamental incompleto, do lar, quando trabalham fora de casa, muitas delas são empregadas domésticas e não tem outra qualificação. $\mathrm{Na}$ análise dos relatórios assim como nas fichas descritas abaixo, a variável cor, permite concluir que a ela não é dada a importância necessária, constata-se em muitos registros a ausência dessa informação, assim como o uso inadequado de outras nomenclaturas como, por exemplo: morena, morena clara, morena escura, nomear parda para uma indígena, embora a grande maioria se denomine pardas, negras e minoritariamente brancas. Pode-se dizer que as usuárias da Casa Abrigo Mãe da Mata em Rio Branco, tem o perfil de mulheres pobres, baixa escolaridade, muitas não alfabetizadas. Não são donas nem mesmo de seus corpos machucados, tem baixa autoestima e são potencialmente necessitadas da assistência do Estado em vários aspectos de suas vidas que vão além da violência sofrida (p. 95).

$\mathrm{Na}$ maioria dos casos as mulheres permanecem na CAMM por um período de 2 a 30 dias (66,45\%), 25,25\% ficam apenas um pernoite. Apenas três ficaram mais de 90 dias - o tempo definido como máximo para a permanência (ACRE, 2005). O tipo de violência mais referida é a ameaça de morte (46,98\%), seguida da violência física $(35,43 \%)$. As violências sexuais $(7,09 \%)$ e psicológicas $(6,82 \%)$ ainda são pouco identificadas pelas mulheres. 0 maior número de encaminhamentos vem da Delegacia Especializada de Atendimento à Mulher - DEAM (75,75\%) (ACRE, 2005).

No momento do desligamento da CAMM, observa-se que 63,55\% das mulheres que estavam sofrendo violência sob risco de morte, quebraram o ciclo da violência, ou seja, não retornaram para a convivência com o autor da violência. No entanto, 16,26\% voltaram para o agressor ou saem da CAMM sem um desfecho do caso.

Uma questão que passou a ser objeto de observação, mas que não havia registros para uma base de comparação foi a relação das mulheres com as drogas psicotrópicas. Os dados de Alves e Coura-Filho (2001) sobre o uso desses psicofármacos chamaram a atenção: 36\% das mulheres que passaram pela casa-abrigo "Sempre Viva" em Belo Horizonte de 1996 e 1998 fazem/fizeram uso de ansiolítico e antidepressivo. 
Empiricamente, foi observado nas abrigadas da CAMM o uso dessas medicações ou a sua necessidade, entretanto, faz-se necessário investigar o possível consumo e compreender o papel desse tipo de medicação na experiência de viver situações de violência de gênero.

Vale destacar que quanto ao período de permanência das abrigadas na casa-abrigo, o desligamento e o uso de medicamentos psicotrópicos não houve relato no estudo de Nascimento (20013). Quanto ao tipo de violência sofrida, o estudo não aponta dados quantitativos, mas registra a continuidade na ocorrência de violência física, psicológica e sexual, a partir da análise qualitativa dos discursos de suas entrevistadas (NASCIMENTO, 2013).

Outro resultado importante da CC que podemos destacar é o processo de elaboração progressiva do conceito de gênero. Isso se apresenta nas discussões quando a equipe passa a perceber que o cuidado com a criança não era "uma obrigação da mulher" por ela ser mulher e mãe. Começou-se a pensar na paternidade como aspecto muito importante do processo, passou-se a refletir as condições, o contexto em que algumas mulheres engravidam e têm filhos e o quanto isso vai determinar uma maior ou menor responsabilidade para com esses filhos/as. Os julgamentos, baseados em ideais do senso comum, começaram a ser questionados dentro do próprio grupo.

A equipe começou a sentir a necessidade de planejar e avaliar o trabalho que realizava, iniciando os estudos de caso e grupos de estudo para aprofundamento dos temas. Ainda com resultados do processo de CC, pode-se destacar a revisão das atribuições funcionais de cada cargo da CAMM. Antes de sua inauguração, em 2001, houve a definição das atribuições funcionais dos cargos definidos como necessários ao funcionamento inicial da CAMM (Acre, 2001). Entretanto, estas atribuições foram reformuladas com base na experiência de três anos de funcionamento da CAMM e nos estudos das atribuições funcionais - por conta de cargos que passaram a existir, que deixaram de existir e outros que continuaram, mas com outra 
proposta, como por exemplo, o Serviço de Psicologia (PORTO, 2008).

Por fim, um dos momentos significativos da capacitação foi o estudo/conhecimento/ debate sobre o Protocolo de Implementação de casas-abrigo da Secretaria de Políticas Públicas para as Mulheres. A equipe demonstrou interesse pelo texto de referência, esforçando-se para compreender a relação entre o texto e a realidade vivenciada na CAMM que promoveu o reconhecimento do papel das monitoras como fundamental e, por isso, devendo ser incluído na descrição do quadro mínimo necessário para a organização dos recursos humanos de um abrigo para mulheres em situação de violência.

\section{Considerações finais}

0 abrigamento de mulheres que sofrem violência ainda é uma política pública que sofre inúmeras críticas e também defesas significativas. Para ilustrar recorremos a Cabral (1999) que apresenta as políticas de abrigamento nas situações de violência como uma medida preventiva defendida na literatura especializada. Todavia, já na época de seu estudo, apresenta as limitações que essa política enfrenta-funcionamento precário, dificuldade para manter os profissionais capacitados mesmo em regiões onde a magnitude do problema é preocupante. Por fim, conclui que o abrigamento é uma medida preventiva ainda remota e pouco valorizada. Já Brito (1999) analisa a representação ambígua das casas-abrigo, cujo objetivo é oferecer um serviço de proteção às mulheres em situação de risco promovendo proteção à integridade física. No entanto, estar abrigada também é estar presa, mesmo sem ter cometido nenhum crime.

Bybee e Sullivan (2005) investigaram sobre a revitimização de mulheres em situação de violência doméstica que se utilizaram dos serviços de uma casa-abrigo. Nesse estudo observaram que há um impacto positivo na vida daquelas que tiveram assistência jurídica. Contudo, condições de suporte social inadequado quando se encontram egressas do serviço (falta de uma rede social de apoio, recursos insuficientes para 
se manter e falta de suporte de políticas de apoio) traria mais risco de revitimização.

Apesar dessas discussões teóricas, e até mesmo por elas, não se pode negligenciar: há mulheres procurando o abrigo, há uma política pública específica e uma estrutura proposta para seu funcionamento. É nesse contexto, e sem desconsiderar que o abrigamento para mulheres em situação de violência doméstica precisa ser mais bem avaliado e estudado, que defendemos a integração da figura da monitora no quadro mínimo de funcionamento para uma casaabrigo, pois ainda em 2011 a figura da monitora se apresenta como importante na casa abrigo Mãe da Mata. Ainda estamos estudando, perguntando; estamos num processo de construção, que apresentamos para o debate.

\section{Referências}

ACRE, Secretaria de Estado de Cidadania e Assistência Social, Gerência de Equidade de Gênero. Relatório dos abrigamentos. Rio Branco (AC), 2005 (mimeo.).

ACRE, Secretaria de Estado de Cidadania e Assistência Social, Gerência de Eqüidade de Gênero. Atribuições funcionais da Casa Abrigo Mãe da Mata. Rio Branco
(AC), 2003 (mimeo.)

ACRE, Secretaria de Estado de Cidadania e Assistência Social. Casa Abrigo Mãe da Mata. Atribuições funcionais (memória de reunião). Rio Branco (AC), 2001 (mimeo.).

ALVES, A. M.; COURA-FILHO, P. "Avaliação das ações de atenção às mulheres sob violência no espaço familiar, atendidas no Centro de Apoio à Mulher (Belo Horizonte), entre 1996 e 1998". In: Ciência saúde coletiva, Rio de Janeiro, v.6, n. 1, 2001, pp. 243-257.

BRANCALHONE, P. G.; FOGO, J. C.; WILLIAMS, L. C. A. “Crianças expostas à violência conjugal: avaliação do desempenho acadêmico". In: Psicologia: teoria e pesquisa, Brasília, v.20, n.2, maio/ago., 2004, pp.113-117.

BRASIL, Secretaria Especial de Políticas para as Mulheres, Programa de Prevenção, Assistência e Combate à Violência contra a Mulher. Plano Nacional: Diálogos sobre violência doméstica e de gênero - construindo políticas públicas. Brasília: A Secretaria, 2003.

BRITO, B. R. P. "Casa-abrigo: um espaço de apoio e de solidariedade versus uma visão assistencialista". In: Jornal da Redesaúde, n. 19, nov. 1999, pp. 13-14.

BYBEE, D. e SULLIVAN C.M. "Predicting re-victimization of battered women 3 years after exiting a shelter program". In: American Journal of Community Psychology, v. 36, n. 1-2, 2005, pp. 85-96.

CABRAL, M. A. A. "Prevenção da violência conjugal contra a mulher". 
In: Ciência e saúde coletiva, v. 4, n. 1, 1999, pp.183-191.

CAMARGO, M. "Violência e saúde: ampliando políticas públicas". In: Jornal da Redesaúde, São Paulo, n.22, 2000, pp. 6-8.

CAMPOS, L. F. L. Métodos e técnicas de pesquisa em Psicologia. Campinas (SP): Alínea, 2001.

D'OLIVEIRA, A. F.; SCHRAIBER, L. B. "Violência doméstica como problema para a saúde pública: capacitação dos profissionais e estabelecimento de redes intersetoriais de reconhecimento, acolhimento e resposta ao problema". In: Anais do VI Congresso Brasileiro de Saúde Coletiva. Salvador, Brasil, 2000.

DUHAMELE, M.; FORTIN, A. "Justification of violence toward the child by mothers victimized by spousal violence". In: Canada Journal Community Mental Health, v. 25, n. 1, 2004, pp. 47-63.

FRANCO, I. R. "Mulheres em situação de violência doméstica: produção e enfretamento do fenômeno". In: Anais do VI Congresso Brasileiro de Saúde Coletiva, Salvador, Brasil, 2000.

HEISE, L.; PITANGUY, J.; GERMAIN. A. Violence Against Women: The Hidden Health Burden. Washington, D.C: The International Bank for Reconstruction and Development/ The World Bank, 1994.

LOPES, I. M. R. S.; GOMES, K. R. O.; SILVA, B. B.; DEUS, M. C. B. R.; GALVÃO, E. R. C. G. N.; BORBA, D. C. "Caracterização da Violência Sexual em Mulheres Atendidas no Projeto Maria-Maria em Teresina-PI". In:
Revista Brasileira de Ginecologia e Obstetrícia - n RBGO, Rio de Janeiro, v. 26, n. 2, 2004, pp. 111-116.

MALDONADO, D. P. A.; WILLIAMS, L. C. A. "O comportamento agressivo de crianças do sexo masculino na escola e sua relação com a violência doméstica”. In: Psicologia em Estudo, Maringá, v.10, n.3, set./dez. 2005, pp.353-362.

MENEGHEL, S. N.; CAMARGO, M.; FASOLO, L. R. [et al]. "Mulheres cuidando de mulheres: um estudo sobre a Casa de Apoio Viva Maria, Porto Alegre, Rio Grande do Sul, Brasil". In: Cadernos de Saúde Pública, Rio de Janeiro, v.16, n. 3, jul./ set. 2000, pp.747-757.

MENEGHEL, S.; ARMANI, T.; SEVERINO, R. [et al]. "Cotidiano violento: oficinas de promoção em saúde mental em Porto Alegre". In: Ciência Saúde Coletiva, Rio de Janeiro, v.5, n.1, 2000, pp.193-203.

NASCIMENTO, M. R. B. "Eu queria ter uma história bonita pra contar...": Violência conjugal e os (des)caminhos em busca da ruptura. São Paulo: Pontifícia Universidade Católica de São Paulo, 2013 (Dissertação de Mestrado em Ciências Sociais).

PINTO, C. R. J. Uma história do feminismo no Brasil. São Paulo: Editora Fundação Perseu Abramo, 2003.

PORTO, M. A saúde da mulher em situação de violência: o que pensam os gestores e gestoras municipais do Sistema Único de Saúde? Recife: UFPE, 2002 (Dissertação de Mestrado em Saúde Coletiva).

PORTO, M..; MACCALLUM, C.; SCOTT, 
R. P.; MORAIS, H. M. M. "A saúde da mulher em situação de violência: representações e decisões de gestores/as municipais do Sistema Único de Saúde". In: Cadernos de Saúde Pública, Rio de Janeiro, v. 19, supl. 2, pp. 2003, 243-252.

Porto, M. “Intervenção psicológica em Abrigo para Mulheres em situação de violência: uma experiência". In: Psicologia: Teoria e Pesquisa, v. 24, n. 3, 2008, pp. 369-374.

REICHENHEIM, M. E.; HASSELMANN, M.H.; MORAES, C. L. "Conseqüências da violência familiar na saúde da criança e do adolescente: contribuições para a elaboração de propostas de ação".
In: Ciência Saúde Coletiva, Rio de Janeiro, v. 4, n.1, 1999, pp.109-121. SCHRAIBER, L. B ; D'OLIVEIRA, A. F. L. P. "Violência contra a mulher: interfaces com a saúde". In: Interfaces: Comunicação, Saúde, Educação, Botucatu-SP, v. 3, n. 5, 1999, pp. 11-27. SCHRAIBER, L. B; D'OLIVEIRA, A. F. L. P; STRAKE, S. S.; LIBERMAN, M. D. Violência contra a mulher e políticas de saúde no Brasil: o que podem fazer os serviços de saúde? Departamento de Medicina Preventiva/Faculdade de Medicina/ USP, s/d (mimeo.). 